\title{
Article
}

\section{Clinical practice guidelines for Videofluoroscopic Swallowing Studies: A systematic review}

Boaden, Elizabeth, Nightingale, J, Bradbury, C, Hives, Lucy and Georgiou, Rachel

Available at http://clok.uclan.ac.uk/30555/

Boaden, Elizabeth ORCID: 0000-0002-4647-6392, Nightingale, J, Bradbury, C, Hives, Lucy ORCID: 0000-0003-4125-4034 and Georgiou, Rachel (2020)

Clinical practice guidelines for Videofluoroscopic Swallowing Studies: A systematic review. Radiography, 26 (2). pp. 154-162. ISSN 1078-8174

It is advisable to refer to the publisher's version if you intend to cite from the work. http://dx.doi.org/10.1016/j.radi.2019.10.011

For more information about UCLan's research in this area go to http://www.uclan.ac.uk/researchgroups/ and search for <name of research Group>.

For information about Research generally at UCLan please go to http://www.uclan.ac.uk/research/

All outputs in CLoK are protected by Intellectual Property Rights law, including Copyright law. Copyright, IPR and Moral Rights for the works on this site are retained by the individual authors and/or other copyright owners. Terms and conditions for use of this material are defined in the policies page.

\section{CLoK}

Central Lancashire online Knowledge www.clok.uclan.ac.uk

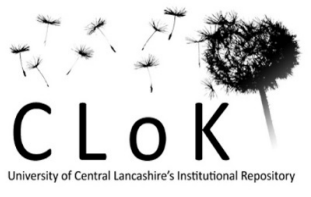




\title{
Clinical practice guidelines for Videofluoroscopic Swallowing Studies: A systematic review
}

\author{
Authors: Boaden E, Nightingale J, Bradbury C, Hives L, Georgiou R.
}

Full reference: Boaden E, Nightingale J, Bradbury C, Hives L, Georgiou R. Clinical practice guidelines for Videofluoroscopic Swallowing Studies: A systematic review. Radiography 2019 (Accepted for publication)

\begin{abstract}
Introduction: Clinical practice guidelines (CPGs) are expected to make evidence-based recommendations, thus guiding practice and reducing unwarranted variation. CPGs are particularly helpful in guiding complex procedures such as the Videofluoroscopic Swallowing Study (VFSS) for the assessment of dysphagia, but there is a suspected high level of variability among them. To explore the extent of this variation, this study aimed to systematically identify and appraise all VFSS CPGs available worldwide.
\end{abstract}

Methods: A systematic search of 3 academic databases and other sources was conducted to identify relevant CPGs; independent reviews of each CPG were undertaken by a Speech and Language Therapist and a Radiographer. Both reviewers completed a pre-determined checklist of expected professional content for each CPG. CPGs were then assessed for quality using the Appraisal of Guidance for Research \& Evaluation II (AGREE II) instrument. Findings from the professional content review and the methodological quality review were synthesised to inform an assessment of suitability of each CPG to inform clinical practice.

Results: Seven VFSS CPGs were identified worldwide, none of which were co-designed by radiographers or aimed at a radiographer audience. Each differs in their professional content, recommendations, underpinning evidence base and professional focus. Average AGREE II scores across the quality domains vary considerably, ranging from 93-22\%. No CPGs scored highly on all six AGREE II domains.

Conclusion: There is no standardisation between VFSS guidelines. Six CPGs are not recommended for clinical use; only one of the seven identified CPGs is recommended for use following significant modification.

Implications for practice: The lack of a comprehensive, evidence-based guideline encourages unwarranted variation in clinical practice which potentially compromises clinical care. Further research is needed to define VFSS best practice. 


\section{BACKGROUND}

The Videofluoroscopic Swallow Study (VFSS), also known as the modified barium swallow, is a dynamic fluoroscopic imaging examination, suitable for individuals of all ages, referred with swallowing difficulties (dysphagia). VFSS enables visualisation and recording of the contrast bolus passage in real time, in relation to movement of the oral, pharyngeal, laryngeal and oesophageal structures [1]. The VFSS has both diagnostic and therapeutic aims, including: identifying structural abnormalities and interrogation of the physiological swallow function; informing appropriate consistencies for oral intake and/or decisions regarding quality of life and assistive nutrition and hydration. The VFSS further helps to explore the impact of compensatory and rehabilitative intervention programmes and assisting the education of the individual and those that influence the patients care [2].

The use of fluoroscopic procedures continues to fall worldwide; in England, for example, demand fell by $2.6 \%$ from an activity of $1,052,750$ in the period $2016 / 17$ reducing to $1,025,330$ in $2017 / 18$ [3]. The demand for VFSS services, however, is likely to continue as it plays an important role in diagnosis and management of individuals with swallowing difficulties. Dysphagia can affect individuals of any age, but as it is often exacerbated in conditions associated with an ageing population (such as stroke and presbyphagia), the demand is likely to continue to increase within ageing populations worldwide [4]. VFSS presents limitations in patient accessibility, favouring the mobile and the cognitively able. Alternative procedures such as Fibreoptic Endoscopic Evaluation of Swallowing (FEES) have demonstrated clinical utility where individuals with swallowing difficulties are unable to access Videofluoroscopy or where it is clinically contraindicated. Further benefits of FEES mean that the sensory characteristics of food and fluid consistencies are not altered by mixing with contrast agents [5]. FEES, however, presents with limitations in visualising aspiration during the swallow and should be considered complimentary rather than a replacement swallowing examination [6].

The VFSS service worldwide has traditionally been consultant radiologist led, involving a speech and language therapist (SLT) with a dysphagia interest working alongside a radiologist. Within these consultant-led services the radiographer is present in a supporting capacity, with responsibility for 
patient care, service workflow, radiation protection of visiting staff and carers, and supporting the radiologist with image acquisition. In some countries however, most notably in the UK, advanced practitioner radiographer led services have become the norm, with a radiographer and speech and language therapist providing the service jointly [7]. Ensuring that the practitioner-led service is safe, effective and evidence-based is clearly a priority.

The VFSS procedure is complex and presents with a potential for variation in clinical approaches. Variations in the education and training of allied health professionals contribute to different approaches to VFSS within and between institutions including patient referral criteria, contrast agents used, patient positioning strategies, food and fluid consistencies delivered, assessment and intervention strategies trialled and recording and reporting protocols. Variation is not solely due to clinical practice preferences but is also affected by equipment availability, resolution of reporting visual display equipment and image storage solutions. For example, the gradual move from Image Intensifiers to Digital Fluoroscopy, and from video tape to digital capture on Picture Archiving and Communication Systems (PACS), will influence the effectiveness of the VFSS procedure. There is known variability in frame and pulse rates used in VFSS [8-11] and in radiation dose and fluoroscopic screening times [7;12], and digital technologies offer greater potential for the radiographer to positively influence VFSS quality and satisfy radiation protection principles [7]. However current practice has often outpaced clinical guidelines which are often based on less efficient technologies that may now no longer represent best practice.

Despite VFSS being regarded as the 'gold standard' for dysphagia investigation $[13,14]$ these significant disparities (both within clinical practice and within the multi-disciplinary evidence base) provide cause for concern. In order to standardise practice for the benefit of patients, Videofluoroscopy practitioners require methodologically sound, evidence-based recommendations in the form of Clinical Practice Guidelines (CPGs). These summarize the best available evidence, facilitate standardisation of care, and improve the allocation and utilisation of finite healthcare resources, thus improving and directing the best use of resources [15]. The potential of CPGs to enhance 
videofluoroscopy practice is dependent on the availability of the evidence, the quality, and the uptake and adoption in practice [15]. Published evidence has revealed that CPGs can improve patient outcomes, patient experience, and quality and safety in healthcare [16]. The aim of this study is to utilise systematic review methodology to identify and critically appraise any VFSS clinical guidelines available worldwide and make recommendations for their suitability to inform clinical practice.

\section{METHODS}

A systematic review of existing VFSS clinical practice guidelines available worldwide was registered and conducted in accordance with a defined protocol (International Prospective Register of Systematic Reviews, CRD42019130130). Ethical approval was not required. The systematic review is reported in line with the Preferred Reporting Items for Systematic Reviews and Meta-analyses (PRISMA) Statement (see Figure 1). 


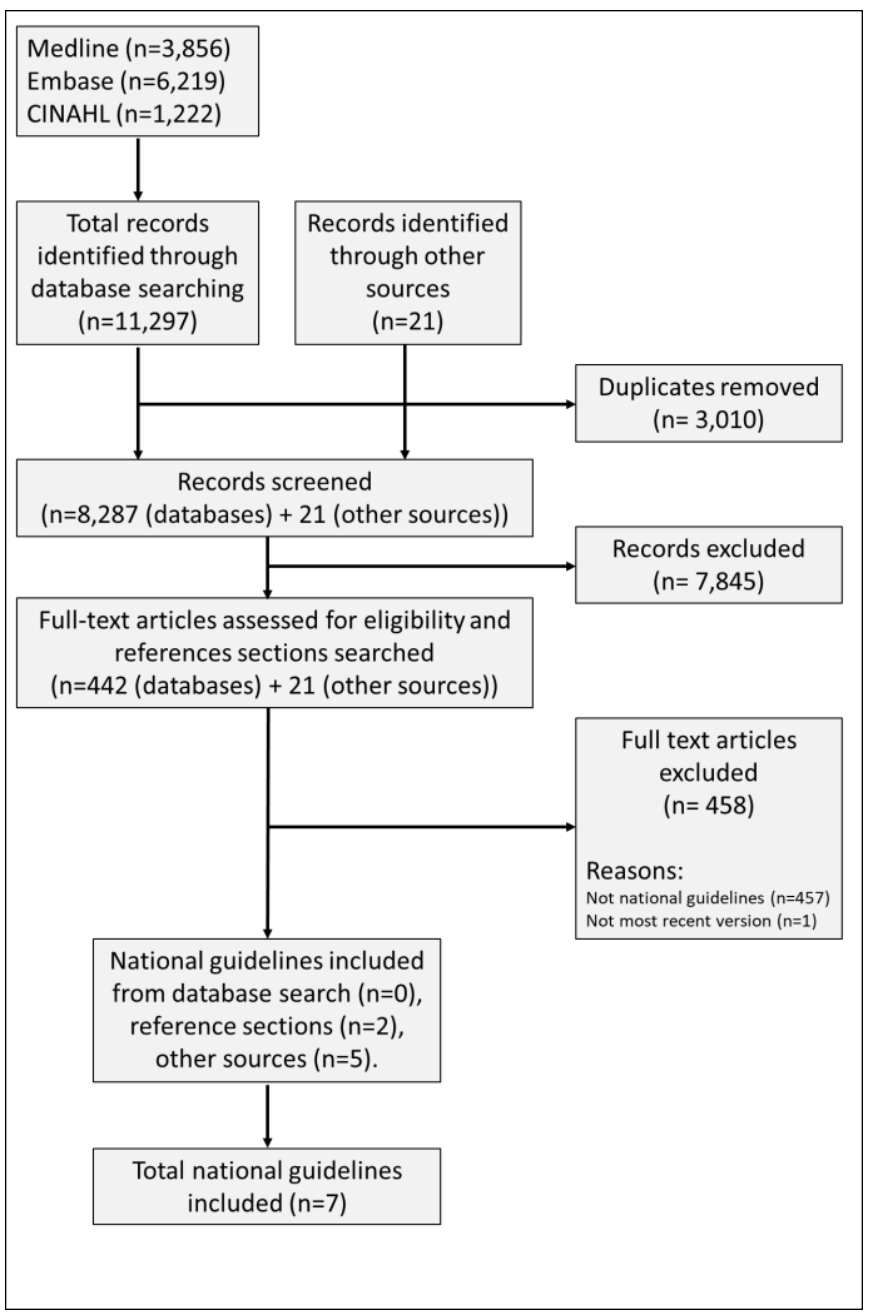

Figure 1: PRISMA flow diagram

\section{Database Search Strategy}

The following electronic academic databases were searched: Ovid MEDLINE (1946 to 13th Nov 2018),

Ovid Embase (1974 to 13th Nov 2018), and EBSCO CINAHL (1961 to 13th Nov 2018). Other sources searched were HMIC Kings Fund Database, Google Search, Prospero, OpenGrey, NICE guidance and the NHS improvements website. The search strategy was designed under the guidance of an information specialist. Keywords and subject headings used were synonyms of the terms "videofluoroscopy", "guideline" and "dysphagia" and the search strategy for Medline is reported fully in Appendix 1. An additional search was undertaken prior to publication to ensure that no additional guidelines had been published between the initial search end date (13.11.2018) and article submission (21.10.19). No relevant documents were identified in this additional search. 


\section{Guideline selection}

The inclusion criteria were any national or professional organisation guidelines for videofluoroscopy or modified barium swallow, written in English. Only the most recent version of a guideline was included. The initial guideline selection process was carried out by two reviewers. Papers identified during the search were managed in EndNote (version X8, Clarivate Analytic Philadelphia, PA). Duplicates were removed and titles and abstracts of remaining papers were screened for relevance. Full texts, including references, were then assessed for inclusion.

\section{Review of Guideline Professional Content (Figures 2 and 3 and Table 2)}

A range of practice-based parameters to be checked was determined by an expert consensus group of four raters with extensive combined expertise in education, research and practice related to VFSS. The expert group included a speech and language therapist (EB) who is a stroke researcher and formerly a clinical consultant dysphagia specialist, a diagnostic radiographer researcher and course leader for videofluoroscopy education (JN), an advanced practitioner diagnostic radiographer and VFSS service lead (CB) and a nurse researcher with stroke care and imaging experience (RG).

Each included CPG was independently analysed by the speech and language therapist and a second individual from the expert group (radiographer or nurse) to provide two different professional perspectives. The two individuals were required to identify the presence or absence of professional content (14 VFSS categories) that could be used to direct and inform clinical practice. Any lack of clarity or differences in professional opinion was then discussed across the expert group and agreement was reached on each of 53 practice-based parameters.

Review of Guideline Methodological Quality (Figure 4 and Table 3) 
The selected national guidelines were assessed for methodological quality using the Appraisal of Guidance for Research \& Evaluation II (AGREE II) instrument [17]. This was chosen as it is the most commonly applied and validated appraisal tool worldwide [18-20] and the only tool found specifically for appraisal of practice guidelines [18-21]. It is considered the 'gold standard' for guideline appraisal [22]. The tool is comprised of 23 items organized into six quality domains: scope and purpose; stakeholder involvement; rigour of development; clarity of presentation; applicability and editorial independence. Each domain item or question is scored on a Likert scale from one to seven, where $1=$ strongly disagree and 7 = strongly agree.

Double blind rating was undertaken independently by a SLT (EB) and a radiographer (JN or CB) to ensure that potentially diverse professional perspectives were captured. For each item, AGREE assessors were asked to record the rationale for their scores in the comment section. Where there was a difference in scores as a result of individual reviewer's interpretation of the question, the scores were resolved by third review and by re-assessing any divergent scores following further discussion.

Each guideline was also assessed by two reviewers for overall quality (again a score from 1 to 7 ) and, based on the number of domains reaching the quality threshold of $60 \%$, whether each would be recommended outright, recommended for use with modifications, or not recommended for use in clinical practice. Reviewers met to agree final scores if there were any discrepancies on these two items.

\section{Data Analysis}

For the professional content review, the number of present items was summed for each guideline.

Final scores for each quality domain were calculated using the algorithm contained within the AGREE II guidance. Descriptive statistics were then used to calculate the mean score for each domain across the seven guidelines. Reflecting the practice used within similar reviews [23], mean scores of $60 \%$ or 
higher were classified as good quality. The mean AGREEII scores for each of the guidelines was not calculated, as the domains may not have been equally weighted.

Inter-rater reliability between appraisers for the AGREE II domain items and overall quality scores were calculated using a linearly Weighted Kappa ( $\kappa_{w}$ ) [24] on SPSS (version 25, IBM Corp, Armonk, NY, USA). A linearly Weighted Kappa is a more suitable alternative to Cohen's Kappa for assessing agreement on Likert scales, as it take into account the potential for varying levels of disagreement between appraisers' scores [24, 25]. It has also been used in similar CPG reviews [26-28].

\section{RESULTS}

Of the 11,318 papers identified, 8,308 titles and abstracts were screened once duplicates had been removed (Fig. 1). Full text articles $(n=463)$ were assessed for eligibility and seven national videofluoroscopy guidelines were included in the final review [1, 29-34]. 457 papers were excluded because they were not national VFSS guidelines and 1 was excluded because it was a previous version of an included guideline. Table 1 shows the general features of the seven included guidelines.

Five of the CPGs (71.5\%) were published between 2004-2013 [1,29,31,32,34], with two CPGs being published more recently, in 2017 [30,33]. The seven guidelines represented six countries: Australia, Canada, Hong Kong, New Zealand, UK and USA. Six (85.7\%) were written as guidance for SLTs, and one for radiologists [33]. None were developed for use by radiographers. Two CPGs [30,31] were endorsed by a second professional organisation. 
Table 1: General features of the included VFSS CPGs. *Reformatted 2016.

\begin{tabular}{|c|c|c|c|c|c|}
\hline Author & Guideline title & Year & Country & $\begin{array}{c}\text { Profession } \\
\text { of intended } \\
\text { user }\end{array}$ & Endorsements \\
\hline $\begin{array}{l}\text { The Speech } \\
\text { Pathology } \\
\text { Association of } \\
\text { Australia limited } \\
\text { [1] }\end{array}$ & $\begin{array}{l}\text { Clinical Guideline- } \\
\text { Videofluoroscopic swallow } \\
\text { study. }\end{array}$ & 2013 & Australia & SLT & $\mathrm{N} / \mathrm{A}$ \\
\hline $\begin{array}{l}\text { College of } \\
\text { Audiologists and } \\
\text { Speech-language } \\
\text { Pathologists of } \\
\text { Ontario [29] } \\
\end{array}$ & $\begin{array}{l}\text { Practice standards and } \\
\text { guidelines for dysphagia } \\
\text { intervention by speech - } \\
\text { language pathologists. }\end{array}$ & $2007 *$ & Canada & SLT & $\mathrm{N} / \mathrm{A}$ \\
\hline $\begin{array}{l}\text { Hong Kong } \\
\text { Institute of Speech } \\
\text { Therapists Limited } \\
\text { [30] }\end{array}$ & $\begin{array}{l}\text { Guideline of Videofluoroscopic } \\
\text { Swallowing Study (VFSS) in } \\
\text { Speech Therapy }\end{array}$ & 2017 & $\begin{array}{l}\text { Hong } \\
\text { Kong }\end{array}$ & SLT & $\begin{array}{l}\text { HKIST } \\
\text { Professional } \\
\text { Council }\end{array}$ \\
\hline $\begin{array}{l}\text { The New Zealand } \\
\text { Speech-language } \\
\text { Therapists' } \\
\text { Association [31] }\end{array}$ & $\begin{array}{l}\text { New Zealand Speech-language } \\
\text { Therapy clinical practice } \\
\text { guideline on videofluoroscopic } \\
\text { study of swallowing (VFSS). }\end{array}$ & 2011 & $\begin{array}{c}\text { New } \\
\text { Zealand }\end{array}$ & SLT & $\begin{array}{l}\text { The Royal } \\
\text { Australian and } \\
\text { New Zealand } \\
\text { College of } \\
\text { Radiologists }\end{array}$ \\
\hline $\begin{array}{l}\text { Royal College of } \\
\text { Speech and } \\
\text { Language } \\
\text { Therapists [32] }\end{array}$ & $\begin{array}{l}\text { Videofluoroscopic evaluation of } \\
\text { oropharyngeal swallowing } \\
\text { function. The role of speech } \\
\text { and language therapists. RCSLT } \\
\text { Position Paper. }\end{array}$ & 2013 & UK & SLT & N/A \\
\hline $\begin{array}{l}\text { American College } \\
\text { of Radiology (ACR) } \\
\text { [33] }\end{array}$ & $\begin{array}{l}\text { ACR-SPR practice parameter for } \\
\text { the performance of the } \\
\text { modified barium swallow }\end{array}$ & 2017 & USA & Radiologists & $\mathrm{N} / \mathrm{A}$ \\
\hline $\begin{array}{l}\text { American Speech- } \\
\text { language-hearing } \\
\text { Association (ASHA) } \\
{[34]}\end{array}$ & $\begin{array}{l}\text { Guidelines for Speech-language } \\
\text { pathologists performing } \\
\text { videofluoroscopic swallowing } \\
\text { studies. }\end{array}$ & 2004 & USA & SLT & $\mathrm{N} / \mathrm{A}$ \\
\hline
\end{tabular}

\section{Review of Professional content}

Figures 2 and 3 demonstrate the VFSS Procedure and VFSS Governance professional content review outcomes. Some of the 14 VFSS categories assessed were reasonably well documented across most guidelines, including the background, scope of practice and risk management sections. However within each of these sections some of the individual practice-based parameters were poorly expressed; for example in the risk management category only two CPGs [1;29] documented infection control and food safety to a sufficient level of detail (Figure 3). Guidance on Models of Practice, and 
the required education, training, competency and credentials required was sparse in most of the guidelines.

The content scores for each guideline were summed to provide an indication of the breadth and depth of professional content. Table 2 demonstrates that the Australian CPG [1] scored the highest with 77\% of the total available marks, and the Hong Kong CPG [30] scoring the lowest with $30 \%$.

\begin{tabular}{|c|c|c|c|c|c|c|c|c|}
\hline \multirow[b]{2}{*}{$\begin{array}{l}\text { VFSS } \\
\text { Procedure } \\
\text { Category }\end{array}$} & \multirow[b]{2}{*}{$\begin{array}{l}\text { Practice-based } \\
\text { parameter }\end{array}$} & \multicolumn{7}{|c|}{ CPGs with references } \\
\hline & & $\begin{array}{l}\text { Austra } \\
\text { lia } \\
{[1]}\end{array}$ & $\begin{array}{l}\text { Canad } \\
\text { a } \\
{[29]}\end{array}$ & $\begin{array}{l}\text { Hong } \\
\text { Kong } \\
{[30]}\end{array}$ & $\begin{array}{c}\text { New } \\
\text { Zealan } \\
d \\
{[31]}\end{array}$ & $\begin{array}{l}\text { UK } \\
{[32]}\end{array}$ & $\begin{array}{l}\text { USA } \\
\text { ACR } \\
{[33]}\end{array}$ & $\begin{array}{l}\text { USA } \\
\text { ASHA } \\
{[34]}\end{array}$ \\
\hline \multirow{2}{*}{$\begin{array}{l}\text { Backgrou } \\
\text { nd }\end{array}$} & Aim of guideline & & & & & & & \\
\hline & Definition of VFSS & & & & & & & \\
\hline \multicolumn{9}{|c|}{$\begin{array}{l}\text { Each guideline provides sufficient preamble to the purpose of the guideline and provides their definition of } \\
\text { VFSS. }\end{array}$} \\
\hline \multirow[t]{2}{*}{$\begin{array}{l}\text { Scope of } \\
\text { Practice }\end{array}$} & $\begin{array}{l}\text { Patient Inclusion / } \\
\text { exclusion criteria }\end{array}$ & & & & & & & \\
\hline & $\begin{array}{l}\text { Complex vs non- } \\
\text { complex cases }\end{array}$ & & & & & & & \\
\hline \multicolumn{9}{|c|}{$\begin{array}{l}\text { Each guideline prescribes local inclusion/exclusion criteria. On the whole the guidelines contain some } \\
\text { guidance for complex and non-complex cases, this is however limited in two guidelines and absent in one } \\
\text { guideline. }\end{array}$} \\
\hline \multirow{5}{*}{$\begin{array}{l}\text { VFSS } \\
\text { Team and } \\
\text { Models of } \\
\text { Practice }\end{array}$} & $\begin{array}{l}\text { Imaging equipment } \\
\text { operator }\end{array}$ & & & & & & & \\
\hline & $\begin{array}{l}\text { Other professionals in } \\
\text { VFSS team }\end{array}$ & & & & & & & \\
\hline & $\begin{array}{l}\text { Private/external } \\
\text { providers in VFSS }\end{array}$ & & & & & & & \\
\hline & $\begin{array}{l}\text { Collaborative SLT- } \\
\text { radiology service }\end{array}$ & & & & & & & \\
\hline & $\begin{array}{l}\text { SLT / practitioner led } \\
\text { VFSS service }\end{array}$ & & & & & & & \\
\hline \multicolumn{9}{|c|}{$\begin{array}{l}\text { All guidelines have a uni-professional focus; six =SLT, one = radiologist. All guidelines recognised the } \\
\text { collaborative nature of VFSS, but only two referred to practitioner-led services. The role of the radiographer } \\
\text { was poorly defined. }\end{array}$} \\
\hline \multirow{2}{*}{$\begin{array}{l}\text { Pre- } \\
\text { assessme } \\
\text { nt for } \\
\text { VFSS }\end{array}$} & Referral criteria & & & & & & & \\
\hline & $\begin{array}{l}\text { Patient and carer } \\
\text { information }\end{array}$ & & & & & & & \\
\hline \multicolumn{9}{|c|}{$\begin{array}{l}\text { Some guidelines promoted the use of VFSS videos and images as a tool for informing patients about their } \\
\text { management decisions. Referral criteria were poorly described across all guidelines. }\end{array}$} \\
\hline \multirow{4}{*}{$\begin{array}{l}\text { Equipmen } \\
\mathrm{t} \\
\text { considera } \\
\text { tions }\end{array}$} & $\begin{array}{l}\text { Medical imaging } \\
\text { equipment }\end{array}$ & & & & & & & \\
\hline & $\begin{array}{l}\text { AV equipment and } \\
\text { sound recording }\end{array}$ & & & & & & & \\
\hline & $\begin{array}{l}\text { Equipment to mobilise / } \\
\text { position }\end{array}$ & & & & & & & \\
\hline & $\begin{array}{l}\text { Accessory and medical } \\
\text { equipment }\end{array}$ & & & & & & & \\
\hline
\end{tabular}


Generalised absence in radiographic equipment considerations. More discussion surrounding use of AV equipment, documentation and mobilisation. Some guidelines omitted discussion of emergency medical equipment

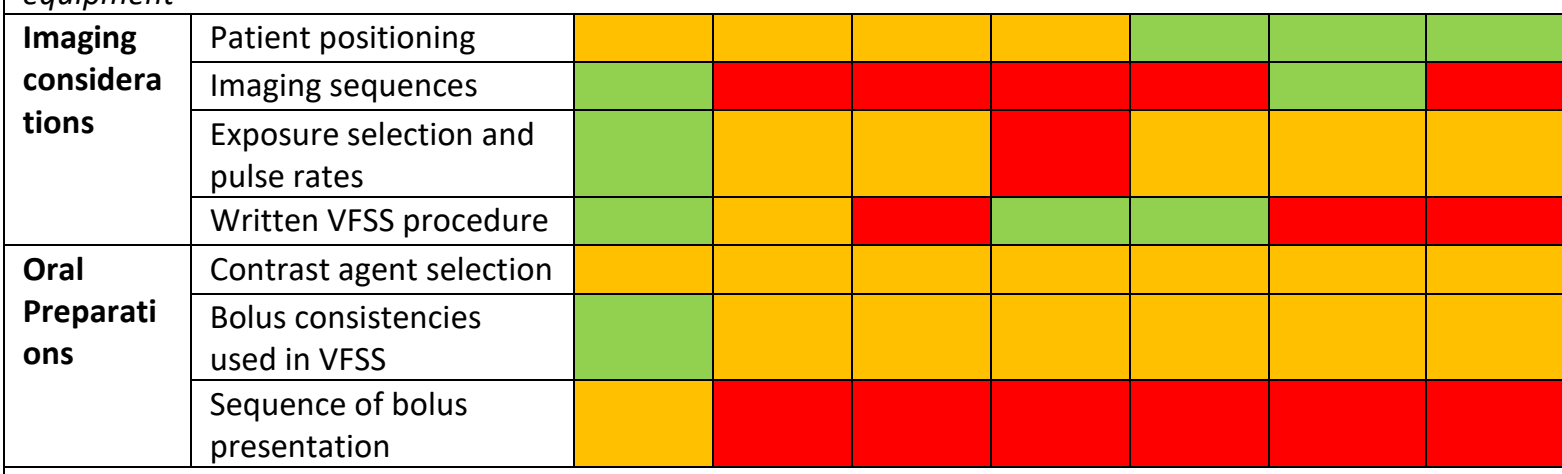

Australian CPG contained all relevant parameters in this sections. Where recommendations were available for some of the parameters, they were lacking in detail and underpinning evidence to support the recommendation.

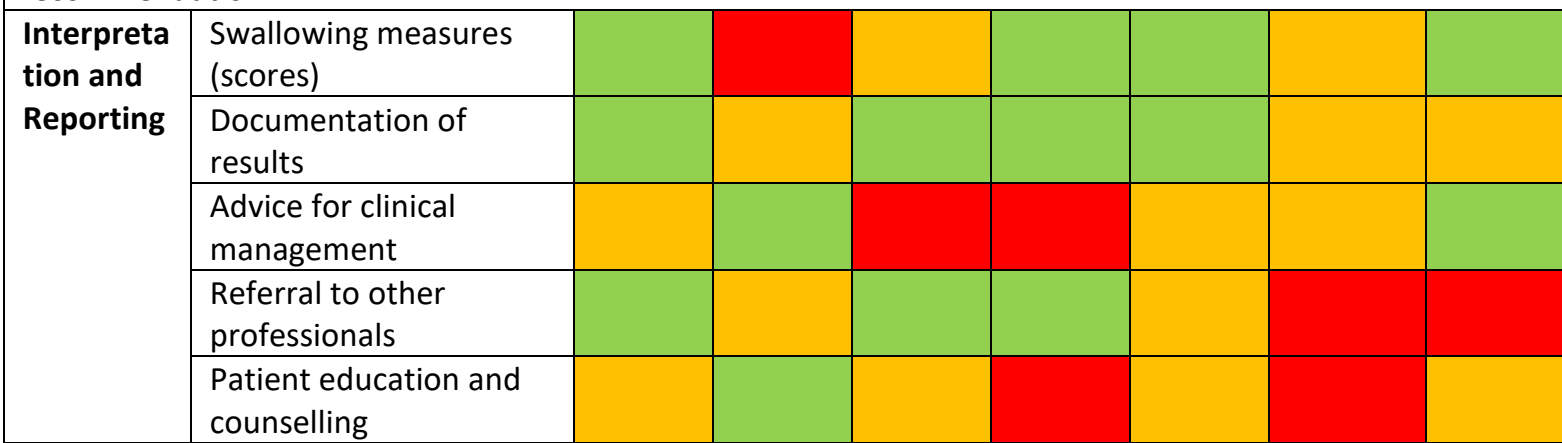

Some CPGs provided detailed explanation of VFSS reporting requirements, including use of validated scales, others provided sparse guidance. Referrals to MDT, referring clinicians and direct to patients was poorly outlined.

Figure 2: Professional content review of each included guideline using VFSS Procedure predetermined categories and practice-based parameters. [Key: Green=included; amber=poorly described; red=not included]

\begin{tabular}{|c|c|c|c|c|c|c|c|c|}
\hline \multirow[b]{2}{*}{$\begin{array}{l}\text { VFSS } \\
\text { Governa } \\
\text { nce } \\
\text { Category }\end{array}$} & \multirow[b]{2}{*}{$\begin{array}{l}\text { Practice-based } \\
\text { parameter }\end{array}$} & \multicolumn{7}{|c|}{ CPGs with references } \\
\hline & & $\begin{array}{l}\text { Austr } \\
\text { alia } \\
{[1]}\end{array}$ & $\begin{array}{c}\text { Cana } \\
\text { da } \\
{[29]}\end{array}$ & $\begin{array}{l}\text { Hong } \\
\text { Kong } \\
{[30]}\end{array}$ & $\begin{array}{l}\text { New } \\
\text { Zeal } \\
\text { and } \\
{[31]}\end{array}$ & $\begin{array}{c}\text { UK } \\
\text { [32] }\end{array}$ & $\begin{array}{l}\text { USA } \\
\text { ACR } \\
\text { [33] }\end{array}$ & $\begin{array}{c}\text { USA } \\
\text { ASH } \\
\text { A } \\
{[34]}\end{array}$ \\
\hline \multirow{7}{*}{$\begin{array}{l}\text { Risk } \\
\text { manage } \\
\text { ment }\end{array}$} & $\begin{array}{l}\text { Radiation } \\
\text { considerations }\end{array}$ & & & & & & & \\
\hline & $\begin{array}{l}\text { Staff radiation } \\
\text { monitoring }\end{array}$ & & & & & & & \\
\hline & $\begin{array}{l}\text { Limiting radiation } \\
\text { exposure }\end{array}$ & & & & & & & \\
\hline & $\begin{array}{l}\text { Pregnancy (staff } \\
\text { and patients) }\end{array}$ & & & & & & & \\
\hline & $\begin{array}{l}\text { Terminating } \\
\text { (adverse } \\
\text { incidents) }\end{array}$ & & & & & & & \\
\hline & $\begin{array}{l}\text { Infectious } \\
\text { diseases }\end{array}$ & & & & & & & \\
\hline & $\begin{array}{l}\text { Food safety } \\
\text { practices }\end{array}$ & & & & & & & \\
\hline
\end{tabular}




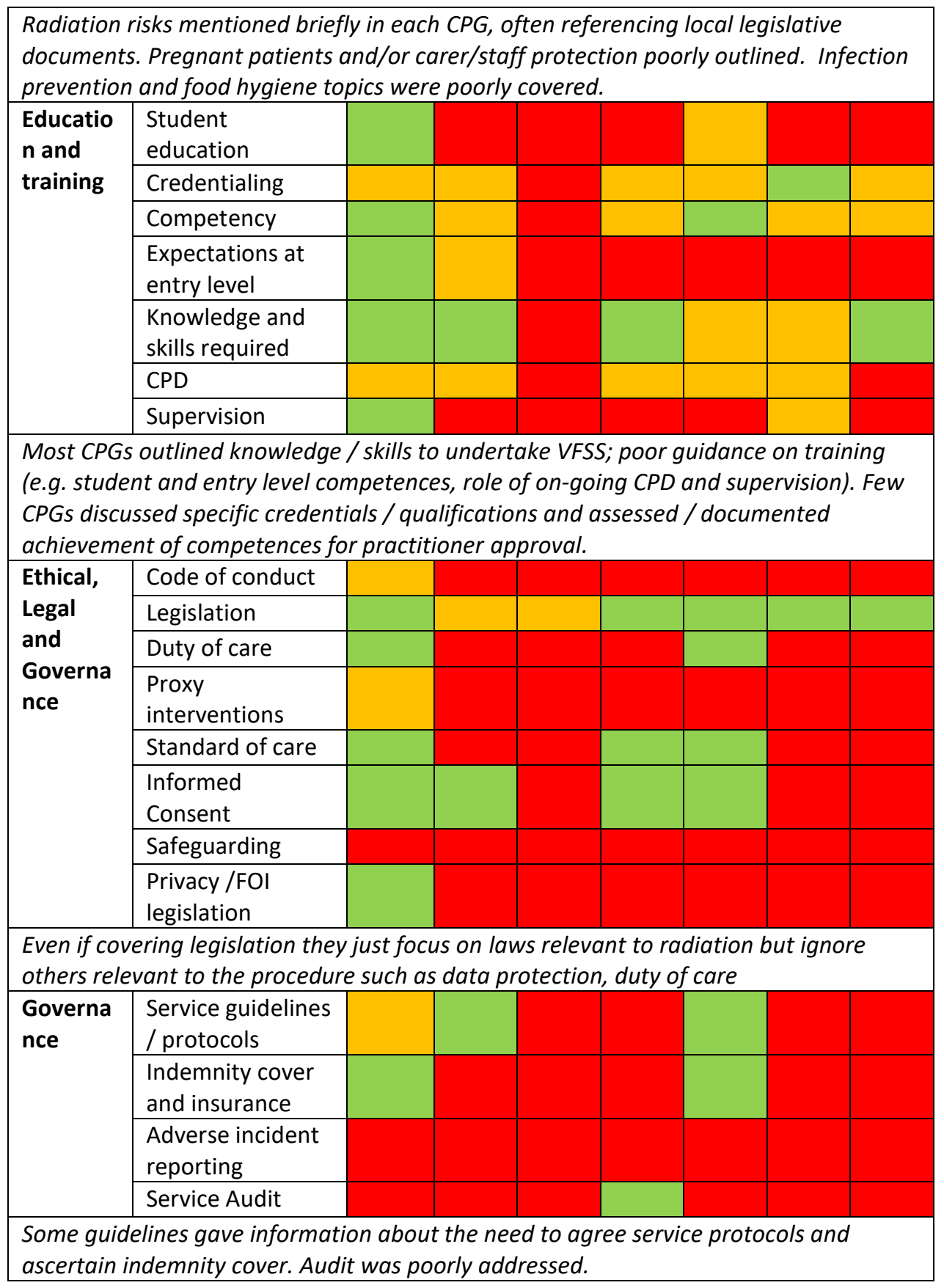

Figure 3: Professional content review of each included guideline using pre-determined VFSS Governance categories and practice-based parameters. [Key: Green=included; amber=poorly described; red=not included]

\section{Review of Guideline methodological quality}

Table 3 and Figure 4 show the final AGREE II domain scores for each guideline. High scores denote a closer alignment to the AGREE II quality criteria, with $60 \%$ selected as the 'good alignment' threshold for each domain. 
A wide range of scores across each quality domain is illustrated, with all guidelines scoring highest in the 'scope and purpose' domain (median 97\%; mean 91.71\%; range 67-100\%), reporting their objective, a specific health question and intended patient groups. The majority of guidelines scored below the $60 \%$ quality threshold on the following domains 'stakeholder involvement' (median 36\%; mean 44.71; range 33-64\%), 'rigour of development' (median 22\%, mean 30.29\%; range 8-59\%) and 'clarity of presentation' (median 50\%; mean 51.57\%; range 14-75\%). These scores highlight an absence of patient, service users and carer representation, as well as a lack of appropriate professional representation inclusive of the multi-disciplinary team. They also highlight an absence of systematic methods for identifying and reviewing the evidence base and using this information to inform the guideline, and a lack of a clear description of different management options for swallowing problems.

All guidelines scored $50 \%$ or less across both the 'applicability' (median 22\%; mean 22.57; range 243\%) and 'editorial independence' (median 17\%; mean 21.57; range 0-50\%) domains. Therefore, most guidelines did not report facilitators and barriers to utilising the CPG, resource implications, advice on how to put the recommendations into practice, monitoring and auditing criteria and competing interest statements relating to the funding body and development group.

\begin{tabular}{|c|c|c|c|c|c|c|c|c|c|c|}
\hline Domain & Description & $\begin{array}{l}\text { Austr } \\
\text { alia } \\
{[1]}\end{array}$ & $\begin{array}{c}\text { Cana } \\
\text { da } \\
{[29]}\end{array}$ & $\begin{array}{l}\text { Hong } \\
\text { Kong } \\
{[30]}\end{array}$ & $\begin{array}{c}\text { New } \\
\text { Zealan } \\
\text { d } \\
{[31]}\end{array}$ & $\begin{array}{l}\text { UK } \\
{[32} \\
]\end{array}$ & $\begin{array}{l}\text { USA } \\
\text { ACR } \\
\text { [33] }\end{array}$ & $\begin{array}{c}\text { USA } \\
\text { ASH } \\
\text { A } \\
{[34]}\end{array}$ & $\begin{array}{c}\text { Mean } \\
\text { doma } \\
\text { in } \\
\text { score } \\
(\%)\end{array}$ & $\begin{array}{c}\text { Medi } \\
\text { an } \\
\text { doma } \\
\text { in } \\
\text { score } \\
\text { (\%) }\end{array}$ \\
\hline $\begin{array}{l}\text { Scope and } \\
\text { Purpose }\end{array}$ & $\begin{array}{l}\text { Outlines specific healthcare } \\
\text { problem, the population to } \\
\text { whom this guideline is } \\
\text { intended. }\end{array}$ & $97 \%$ & $67 \%$ & $97 \%$ & $100 \%$ & $\begin{array}{l}97 \\
\%\end{array}$ & $92 \%$ & $92 \%$ & $\begin{array}{c}91.71 \\
\%\end{array}$ & $97 \%$ \\
\hline $\begin{array}{l}\text { Stakeholder } \\
\text { involvement }\end{array}$ & $\begin{array}{l}\text { Extent to which stakeholders } \\
\text { and potential users have } \\
\text { developed the guideline. }\end{array}$ & $50 \%$ & $33 \%$ & $33 \%$ & $64 \%$ & $\begin{array}{l}36 \\
\%\end{array}$ & $33 \%$ & $64 \%$ & $\begin{array}{c}44.71 \\
\%\end{array}$ & $36 \%$ \\
\hline $\begin{array}{l}\text { Rigour of } \\
\text { development }\end{array}$ & $\begin{array}{l}\text { Process for synthesising CPG } \\
\text { evidence, methods to } \\
\text { formulate recommendations, } \\
\text { review processes. }\end{array}$ & $57 \%$ & $11 \%$ & $8 \%$ & $59 \%$ & $\begin{array}{l}17 \\
\%\end{array}$ & $38 \%$ & $22 \%$ & $\begin{array}{c}30.29 \\
\%\end{array}$ & $22 \%$ \\
\hline $\begin{array}{l}\text { Clarity of } \\
\text { presentation }\end{array}$ & $\begin{array}{l}\text { The language, structure, and } \\
\text { format of the guideline. }\end{array}$ & $67 \%$ & $75 \%$ & $14 \%$ & $61 \%$ & $\begin{array}{l}50 \\
\%\end{array}$ & $50 \%$ & $44 \%$ & $\begin{array}{c}51.57 \\
\%\end{array}$ & $50 \%$ \\
\hline
\end{tabular}




\begin{tabular}{|l|l|c|c|c|c|c|c|c|c|c|}
\hline Applicability & $\begin{array}{l}\text { Barriers and facilitators to } \\
\text { implementation, resource } \\
\text { implications, strategies for } \\
\text { uptake. }\end{array}$ & $38 \%$ & $6 \%$ & $2 \%$ & $29 \%$ & $\begin{array}{c}21 \\
\%\end{array}$ & $43 \%$ & $19 \%$ & $\begin{array}{c}\mathbf{2 2 . 5 7} \\
\mathbf{\%}\end{array}$ & $\mathbf{2 1 \%}$ \\
\hline $\begin{array}{l}\text { Editorial } \\
\text { independence }\end{array}$ & $\begin{array}{l}\text { Potential conflicts of interest of } \\
\text { panel members, role of funding } \\
\text { body or sponsor organisation. }\end{array}$ & $17 \%$ & $0 \%$ & $0 \%$ & $50 \%$ & $\begin{array}{c}46 \\
\%\end{array}$ & $25 \%$ & $13 \%$ & $\begin{array}{c}\mathbf{2 1 . 5 7} \\
\%\end{array}$ & $\mathbf{1 7 \%}$ \\
\hline $\begin{array}{l}\text { Overall quality } \\
(1-7)\end{array}$ & & 5 & 4 & 1 & 6 & 3 & 4 & 4 & & \\
\hline $\begin{array}{l}\text { Recommende } \\
\text { d for clinical } \\
\text { practice? * }\end{array}$ & & No & No & No & $\begin{array}{l}\text { Yes with } \\
\text { modificat } \\
\text { ion }\end{array}$ & No & No & No & & \\
\hline
\end{tabular}

* A guideline is 'recommended' if most of the domains (4 or more) scored above the $60 \%$ quality threshold. A guideline is 'recommended with modifications' if 3 or more domain items scored above $60 \%$. A guideline is 'not recommended' if 4 or more domains score less than $60 \%$.

Table 3 AGREE II domain percentage scores for seven national VFSS guidelines. Scores above the $60 \%$ quality threshold in each domain are highlighted.

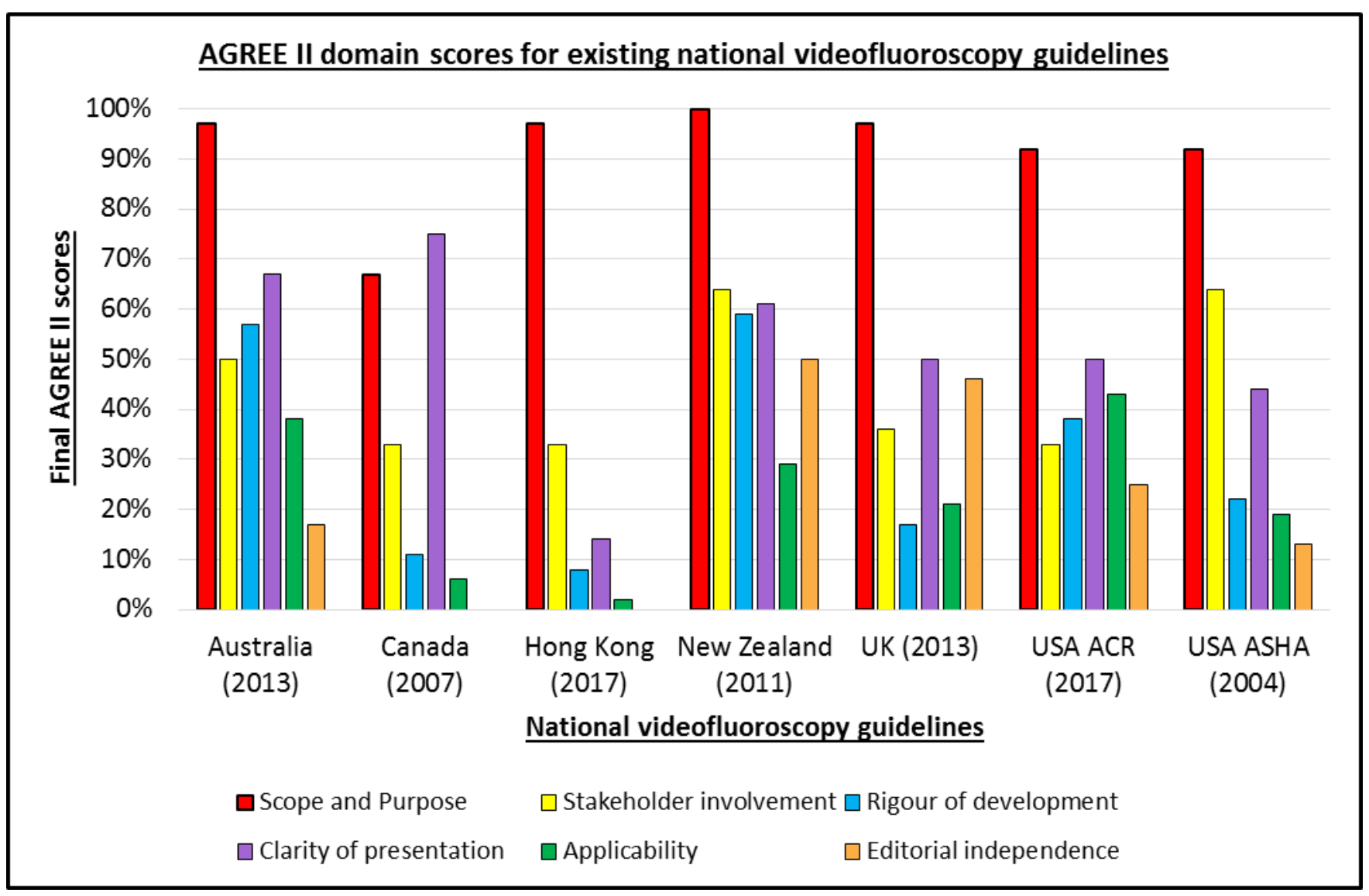

Figure 4 Visual representation of AGREE II domain scores for seven national guidelines. The broken line signifies the $60 \%$ quality threshold value. 


\section{Overall guideline assessment}

The Hong Kong CPG [30] scored lowest on five out of six domains and appraisers gave it an overall rating of 1 (very poor). The New Zealand guideline [31], however, achieved the highest score in four of the six AGREE II domains and achieved the highest overall quality rating of 6 . Despite this, following an objective assessment of numbers of domains achieving the quality threshold of $60 \%$, appraisers would only recommend this CPG with modifications. All other guidelines achieved insufficient quality threshold marks across the six domains to be recommended for clinical practice.

\section{Appraiser's consistency}

Weighted Kappa [24] tests of agreement between assessors on the 23 AGREE II domain items and the overall quality rating (Table 4) revealed values between substantial $\mathrm{K}_{\mathrm{w}}=0.67(95 \% \mathrm{Cl}$ : $0.49-0.84)$ and almost perfect $\mathrm{K}_{\mathrm{w}}=0.87(95 \% \mathrm{Cl}: 0.78-0.96)$ agreement for each guideline [35]. Assessors fully agreed on whether they would recommend each guideline for use in clinical practice.

\begin{tabular}{|l|c|c|}
\hline Clinical guideline & $\begin{array}{c}\text { Weighted } \\
\text { Kappa }\end{array}$ & P-value \\
\hline Australia & 0.73 & $<0.001$ \\
\hline Canada & 0.67 & $<0.001$ \\
\hline Hong Kong & 0.85 & $<0.001$ \\
\hline New Zealand & 0.80 & $<0.001$ \\
\hline UK & 0.67 & $<0.001$ \\
\hline USA ACR & 0.87 & $<0.001$ \\
\hline USA ASHA & 0.77 & $<0.001$ \\
\hline
\end{tabular}

Table 4 Appraiser consistency assessment across AGREE II domain items and overall quality rating scores 


\section{DISCUSSION}

The seven VFSS CPGs identified and analysed within this study were published over a 14-year period from 2004 to 2017 with only two being published within the last five years. In light of professional and technological innovations being implemented in recent years, this raises concerns that the content of some may be outdated. The seven guidelines represent geographical variations across 4 continents ( 6 countries), but it is evident that low- and middle-incomes countries (LMIC) are not represented. The resource availability gap is often wide in LMIC, not only in financial terms but also in terms of the available workforce (the SLT profession is not universally implemented; many countries have a very limited radiographer scope of practice). LMICs therefore need to adapt high quality evidence-based guidelines to their own context. Unfortunately, the results of our study demonstrate that these seven guidelines, all produced within high income countries, are not reflective of current advances in clinical practice. We acknowledge the potential limitation of applying language restrictions to the search strategy due to tight financial and time windows; all CPGs identified emanated from countries with English as a first or commonly spoken language.

The included CPGs are poor in terms of both methodological quality and, for many, professional content. Five out of six AGREE II domains were awarded low mean scores across all CPGs. Following an objective assessment based on whether the domains reached the quality threshold of $60 \%$, six of the CPGs included in this review are not recommended for clinical practice. Only one guideline was recommended for clinical practice with modifications (New Zealand). The New Zealand CPG [31] has the highest overall quality score of 6 , along with 3 out of 6 domain scores above the quality threshold of $60 \%$, yet even this guideline scores poorly on some of the domains (Applicability and Editorial Independence). The selection of the $60 \%$ score as a quality cut-off point is contentious, as the AGREE II instrument does not mandate any particular cut-off point [36], though it has been used in previous studies [36]. Interestingly, this guideline did not score highest overall in the professional content assessment which is assessing different criteria. As with all guidelines there were, however, aspects 
of content that were noteworthy; in this case the reviewers praised the useful appendices and recognised the efforts to tailor the wording to the local context.

While the domains of Editorial Independence, Applicability and Rigour of Development were awarded the lowest average scores across the guidelines, this is not unique to videofluoroscopy, with these domains scoring low in many other guideline reviews [16;28;37-38]. Amer et al contest that Rigour of Development is the largest AGREE II domain [36] and is arguably the core of the AGREE II instrument [36;37], so it is a concern that 5 out of 7 guidelines in our review score very poorly in this domain (mean $=30 \%$ ). This domain evaluates whether the guidelines use a robust systematically searched evidence base that is critically appraised by a development team with broad clinical and technical expertise [38]. With the exception of two CPGs [1;31], the evidence base used was restricted (low number of references) and poorly selected (weak studies). Most failed to report systematic methods and the selection criteria for the evidence used, the strengths and limitations of the body of evidence and the how the evidence informed recommendations given. It was not clear whether guidelines had been externally reviewed by experts and what the planned procedure was for updating the guidelines. While some CPGs suggested a review at approximately 5 years, only two CPGs supplied a definitive document review date. The Hong Kong CPG review date of 2020 had not yet been reached [30], however the UK CPG should have been reviewed three years previously in 2016 [32].

Most guidelines scored poorly on all questions for the Applicability domain, meaning that they failed to do the following: describe facilitators and barriers to its application, provide advice and/or tools on how the recommendations can be put into practice, consider the potential resource implications of applying the recommendations and present monitoring and/or auditing criteria. This domain supports the translation of research into 'day to day' practice, and the poor scores reflect guidelines with insufficient support and guidance for practitioners.

Editorial independence was also poorly scored for most guidelines. While authors of reports were clearly named, their designations, qualifications and organisations were often omitted, making it 
difficult to assess potential conflicts of interest. Similarly, it is not clear whether the content of the guidelines has been influenced by the funding body or sponsoring organisation.

While the Stakeholder Involvement domain was not the worse scoring category (33-64\%), a number of important issues were raised, particularly for the radiography profession. None of the guidelines included the patients or users of the procedure in their development. Gillespie and colleagues [15] also identified this as an issue in guidelines for surgical site infection, and they note that one of the pillars of evidence-based medicine is patient-centeredness, being respectful of and responsive to the expectations, preferences and experiences of patients [15]. Patient and Public Involvement (PPI) is now a core tenet of the radiography profession [39], encouraging research development processes to include patients at every stage; those developing guidelines should include healthcare users in their membership. However, users of guidelines also include healthcare practitioners; 6 of the 7 guidelines were developed by the Speech and Language Therapists for the Speech and Language Therapist community, with no radiographer input. One guideline had a radiologist authorship, again with no multi-disciplinary input. In some countries, most notably in the UK and Ireland, practitioner-led services have become the norm, with a radiographer and SLT providing the service jointly. All international CPGs take a uni-professional approach, surprising for a procedure that is distinctly multidisciplinary. Radiographers and their role are not represented.

The professional content review also identified content that was out of date, with poor methodologies or based on opinion rather than evidence. All of the guidelines used general statements, with little evidence presented to support the recommendations, and where there is evidence it is often not appraised or rated. Most guidelines offered limited recommendations for practice, and practice has changed since some older guidelines produced. The statements related to radiographer roles (e.g. radiation protection, dose monitoring, image acquisition parameters, image quality and optimisation) were often excluded or very generalised, with little or no evidence to guide practice and subsequent audit. 
As professional remits continue to evolve worldwide and practitioners are redefining the Videofluoroscopy procedure, the role of all professionals involved in the multi-disciplinary team, alongside service user representation, needs to be reflected in any subsequently updated or new guidelines. Any new VFSS guideline development group would be strongly advised to follow the AGREE II framework from the outset to ensure that quality appraisal is embedded in the guideline. However, despite the widespread recognition of the AGREE II tool of choice for the qualitative analysis of clinical guidelines, we did find a requirement for reviewer discussion prior to the review, to agree on the interpretation of the domain questions which were in places lacking clarity. Disagreements in the interpretation of one of the questions led to initial end of scale choices for raters i.e. a score of 1 rather than 7, so for future work it would be beneficial to seek a group consensus on the application of the AGREE II tool prior to individual scoring.

\section{CONCLUSION}

The current paucity and variability in clinical guidelines for Videofluoroscopy available internationally limits the usefulness and objectivity of videofluoroscopy, which should be a reliable instrument to diagnose and inform treatment. There is an urgent need for evidence based guidance and standardised training to inform practice in order to improve reliability, to reduce unnecessary exposure and increase the diagnostic and therapeutic usefulness of this investigation to improve patient care.

This is the first study to systematically evaluate the quality of recently published guidelines available worldwide for management of VFSS in all age groups using the complete AGREE II instrument. Only one of the seven CPGs identified and evaluated within this systematic review can be recommended to guide practice (with modification), therefore we propose that there is an urgent need for a representative multi-disciplinary group to develop VFSS guidelines suitable for contemporary practice. We recommend that this guideline development group should aim to follow the AGREE II criteria to 
improve the standards and quality of the CPG. Embedding the AGREE II appraisal of CPGs in the training and education of healthcare providers is also recommended.

\section{FUNDING}

This project was funded by the LIFE Institute (Lancashire Research Institute for Global Health and Wellbeing)

\section{REFERENCES}

1. The Speech Pathology Association of Australia Limited. Clinical Guideline Videofluoroscopic Swallow Study. 2013.

2. Lee JW, Randall DR, Evangelista LM, Kuhn MA, Belafsky PC. Subjective assessment of videofluoroscopic swallow studies. Otolaryngol Head Neck Surg 2017;156(5):901-5. https://doi.org/10.1177/0194599817691276.

3. NHS England: Diagnostic imaging dataset annual statistical release $2017 / 18$. Available at: https://www.england.nhs.uk/statistics/wp-content/uploads/sites/2/2018/11/Annual-StatisticalRelease-2017-18-PDF-1.6MB-1.pdf. [Last accessed 16 August 2019].

4. Aslam M, Vaezi MF. Dysphagia in the elderly. Gastroenterol Hepatol (N Y). 2013;9(12):784-795.

5. Stokely SL, Molfenter SM, Steele CM. Effects of barium concentration on oropharyngeal swallow timing measures. Dysphagia 2014;29(1):78-82. https://doi.org/10.1007/s00455-013-9485-6.

6. Espitalier F, Fanous A, Aviv J, Bassiouny S, Desuter G, Nerurkar N, et al. International consensus (ICON) on assessment of oropharyngeal dysphagia. Eur Ann Otorhinolaryngol Head Neck Dis 2018;135(1), S17-21. https://doi.org/10.1016/j.anorl.2017.12.009.

7. Earl VJ, Badawy MK. Radiation Exposure to Staff and Patient During Videofluoroscopic Swallowing Studies and Recommended Protection Strategies. Dysphagia 2019;34(3):290-7.

https://doi.org/10.1007/s00455-018-9945-0.

8. Peladeau-Pigeon M, Steele CM. Technical aspects of a videofluoroscopic swallowing study. Canadian Journal of Speech-Language Pathology and Audiology 2013; 37(3):216-26.

9. Peladeau-Pigeon M, Steele C. Understanding image resolution and quality in videofluoroscopy. Perspectives on Swallowing and Swallowing Disorders (Dysphagia) 2015;24(3):115-24. https://doi.org/10.1044/sasd24.3.115.

10. Daniels SK, Easterling CS. Continued relevance of videofluoroscopy in the evaluation of oropharyngeal dysphagia. Curr Radiol Rep 2017;5(6). https://doi.org/10.1007/s40134-017-0201-4.

11. Burns CL, Keir B, Ward EC, Hill AJ, Farrell A, Phillips N, Porter L. A dynamic image quality evaluation of videofluoroscopy images: considerations for telepractice applications. Dysphagia 2015;30(4):473-481. https://doi.org/10.1007/s00455-015-9626-1.

12. Bonilha HS, Humphries K, Blair J, Hill E, McGratton K, Carnes B, et al. Radiation Exposure Time during MBSS: Influence of Swallowing Impairment Severity, Medical Diagnosis, Clinician Experience, 
and Standardized Protocol Use. Dysphagia (2013) 28(1): 77-85. https://doi.org/10.1007/s00455-012$\underline{9415-z 13}$

13. Costa MMB. Videofluoroscopy: the gold standard exam for studying swallowing and its dysfunction. Arq Gastroenterol 2010;47(4):327-328. https://doi.org/10.1590/S000428032010000400001.

14. Edmiaston J, Connor LT, Steger-May K, Ford AL. A simple bedside stroke dysphagia screen, validated against videofluoroscopy, detects dysphagia and aspiration with high sensitivity. J Stroke Cerebrovasc Dis 2014;23(4):712-716. https://doi.org/10.1016/i.jstrokecerebrovasdis.

15. Gillespie BM, Bull C, Walker R, Lin F, Roberts S, Chaboyer W. Quality appraisal of clinical guidelines for surgical site infection prevention: a systematic review. PLoS ONE. 2018;13(9):e0203354. https://doi.org/10.1371/journal.pone.0203354.

16. Sekercioglu N, Al-Khalifah R, Ewusie J, Elias R, Thabane L, Busse J, et al. A critical appraisal of chronic kidney disease mineral and bone disorders clinical practice guidelines using the AGREE II instrument. Int Urol Nephrol. 2017;49(2):273-84.

17. AGREE Next Steps Consortium. The AGREE II Instrument [Electronic version]. Available at http://www.agreetrust.org. [Last accessed 28 August 2019].

18. Brouwers M, Kho ME, Browman GP, Burgers JS, Cluzeau F, Feder G, et al. AGREE II: Advancing guideline development, reporting and evaluation in healthcare. Can Med Assoc J 2010;182:E839-42. https://doi.org/0.1503/cmaj.090449.

19. Brouwers MC, Kho ME, Browman GP, Burgers JS, Cluzeau F, Feder G, et al. Development of the AGREE II, part 1: performance, usefulness and areas for improvement. Can Med Assoc J 2010;182(10):1045-52. https://doi.org/10.1503/cmaj.091714.

20. Brouwers MC, Kho ME, Browman GP, Burgers JS, Cluzeau F, Feder G, et al. Development of the AGREE II, part 2: assessment of validity of items and tools to support application. Can Med Assoc J 2010;182(10):E472-8. https://doi.org/10.1503/cmaj.091716.

21. WHO. RHL: The WHO Reproductive Health Library. Available at: http://apps.who.int/rhl/guidelines/en/index.html. [Last accessed 21 August 2013].

22. Ng JY, Liang L, Gagliardi AR. The quantity and quality of complementary and alternative medicine clinical practice guidelines on herbal medicines, acupuncture and spinal manipulation: systematic review and assessment using AGREE II. BMC Complementary and Alternative Medicine 2016;16:425. DOI 10.1186/s12906-016-1410-8

23. Johnston A, Hsieh S, Carrier M, Kelly SE, Bai Z, Skidmore B, Wells GA. A systematic review of clinical practice guidelines on the use of low molecular weight heparin and fondaparinux for the treatment and prevention of venous thromboembolism: Implications for research and policy decision-making. PLoS ONE 2018;13(11):e0207410. https://doi.org/10.1371/journal.pone.0207410.

24. Cohen J. Weighted Kappa: Nominal scale agreement with provision for scaled disagreement or partial credit. Psychol Bull 1968;70(4):213-20.

25. Tang W, Hu J, Zhang H, Wu P, He H. Kappa coefficient: a popular measure of rater agreement. Shanghai Arch Psychiatry 2015;27(1):62-7. https://doi.org/10.11919/j.issn.1002-0829.215010. 
26. Dersch R, Toews I, Sommer H, Rauer S, Meerpohl JJ. Methodological quality of guidelines for management of Lyme neuroborreliosis. BMC Neurology 2015;15(242).

https://doi.org/10.1186/s12883-015-0501-3

27. Appleyard TL, Mann CH, Khan KS. Guidelines for the management of pelvic pain associated with endometriosis: a systematic appraisal of their quality. BJOG 2006;113(7):749-57.

https://doi.org/10.1111/j.1471-0528.2006.00937.x.

28. Lopez-Vargas PA, Tong A, Sureshkumar P, Johnson DW, Craig JC. Prevention, detection and management of early chronic kidney disease: a systematic review of clinical practice guidelines. Nephrology 2013;18(9):592-604. https://doi.org/10.1111/nep.12119.

29. College of Audiologists and Speech-Language Pathologists of Ontario. Practice Standards and Guidelines for Dysphagia Intervention by Speech-Language Pathologists. 2007.

30. Hong Kong Institute of Speech Therapists Limited. Guideline of Videofluoroscopic Swallowing Study (VFSS) in Speech Therapy. 2017.

31. Miles A, Benoit A, Keesing M, McLauchlan H, Ong E, Rigby H, et al. New Zealand SpeechLanguage Therapy Clinical Practice Guideline on Videofluoroscopic study of swallowing (VFSS). 2011.

32. Royal College of Speech and Language Therapists. Videofluoroscopic evaluation of oropharyngeal swallowing function (VFS): The role of speech and language therapists. RCSLT Position Paper. 2013.

33. American College of Radiology ACR-SPR. Practice Parameter for the Performance of the Modified Barium Swallow. 2017.

34. American Speech-Language-Hearing Association. Guidelines for Speech-language pathologists performing videofluoroscopic swallowing studies. 2004;(suppl 24):77-92.

35. Viera AJ, Garrett JM. Understanding interobserver agreement: the Kappa statistic. Fam Med 2005;37(5):360-3.

36. Amer YS, Al-Joudi HF, Varnham JL, Bashiri AB, Hamad MH, Salehi SM, et al. Appraisal of clinical practice guidelines for the management of attention deficit hyperactivity disorder (ADHD) using the AGREE II Instrument: a systematic review. PLoS ONE 2019;14(17):e0219239.

https://doi.org/10.1371/journal.pone.0219239.

37. Daza JC, Vernooij RWM, Salas K, Osorio D, Cuchi GU. Quality assessment of clinical practice guidelines for chronic kidney disease: a systematic review. BMC Nephrology. 2019;20(192).

https://doi.org/10.1186/s12882-019-1387-x.

38. Appenteng R, Nelp T, Abdelgadir J, Weledji N, Haglund M, Smith E, Obiga O. A systematic review and quality analysis of pediatric traumatic brain injury clinical practice guidelines. PLoS ONE 2018; 13(8):e0201550. https://doi.org/10.1371/journal.pone.0201550.

39. Society and College of Radiographers. Patient Public and Practitioner Partnerships within Imaging and Radiotherapy: Guiding Principles. 14 September 2018, SCoR, London. ISBN: 978-1-909802-23-0

\section{Appendix 1: Medline search strategy}

\begin{tabular}{|l|l|l|l|}
\hline$\#$ & Search & 24 & process* \\
\hline 1 & Videofluoroscop* & 25 & guidance \\
\hline 2 & "video fluoroscop*" & 26 & policy \\
\hline
\end{tabular}




\begin{tabular}{|c|c|c|c|}
\hline 3 & VFSS & 27 & policies \\
\hline 4 & VFSE & 28 & rule \\
\hline 5 & VFSA & 29 & instruction \\
\hline 6 & "dynamic swallow study" & 30 & "scheme of work" \\
\hline 7 & x-ray & 31 & standard \\
\hline 8 & xray & 32 & manual \\
\hline 9 & MBS & 33 & assess* \\
\hline 10 & $\begin{array}{l}\# 1 \text { OR \#2 OR \#3 OR \#4 OR \#5 OR \#6 OR \#7 } \\
\text { OR \#8 OR \#9 }\end{array}$ & 34 & $\begin{array}{l}\# 11 \text { OR \#12 OR \#13 OR \#14 OR \#15 OR \#16 OR } \\
\# 17 \text { OR \#18 OR \#19 OR \#20 OR \#21 OR \#22 OR } \\
\# 23 \text { OR \#24 OR \#25 OR \#26 OR \#27 OR \#28 OR } \\
\# 29 \text { OR \#30 OR \#31 OR \#32 OR \#33 }\end{array}$ \\
\hline 11 & Guidelines as topic/st [standards] & 35 & Deglutition/ \\
\hline 12 & Health planning guidelines/ & 36 & Deglutition disorders/ \\
\hline 13 & Practice guidelines as topic/st [standards] & 37 & dysphagia \\
\hline 14 & Guideline/ & 38 & swallow \\
\hline 15 & Practice guideline/ & 39 & swallow* \\
\hline 16 & Standard of care/ & 40 & pharynx* \\
\hline 17 & Clinical protocols/ & 41 & globus \\
\hline 18 & Health policy/ & 42 & deglutition \\
\hline 19 & guide* & 43 & oropharyngeal \\
\hline 20 & procedure & 44 & oral pharyngeal \\
\hline 21 & recommend* & 45 & $\begin{array}{l}\# 35 \text { OR \#36 OR \#37 OR \#38 OR \#39 OR \#40 OR } \\
\# 41 \text { OR \#42 OR \#43 OR \#44 }\end{array}$ \\
\hline 22 & protocol & 46 & \#10 AND \#34 AND \#45 \\
\hline 23 & practic* & & \\
\hline
\end{tabular}

